\title{
Transição demográfica e desigualdades sociais no Brasil
}

\author{
Fausto Brito*
}

\begin{abstract}
O artigo analisa a originalidade da transição demográfica no Brasil determinada pelos fortes desequilíbrios regionais e sociais. Ainda que única, enquanto um processo global que atinge toda a sociedade brasileira, a transição demográfica apresenta-se como múltipla, pois se manifesta diferentemente segundo as diversidades regionais e, principalmente, sociais. Nessa perspectiva, a transição demográfica está longe de ser considerada neutra: pode tanto criar possibilidades demográficas que potencializem o crescimento da economia e do bem-estar social da população, quanto ampliar as graves desigualdades sociais que marcam a sociedade brasileira. Essa situação torna-se mais complexa em função de o Brasil ainda estar inserido no grande ciclo de crescimento absoluto da sua população. Devido às desigualdades sociais e às correspondentes diferenças nas taxas de fecundidade total, a população mais pobre é a que mais tem crescido, com fortes conseqüências sobre as mudanças na estrutura etária. As relações entre os diversos indicadores da transição demográfica e a renda domiciliar per capita mostram que as diferenças sociais levam, no Brasil, a "desigualdades demográficas" maiores do que aquelas observadas entre as diferentes regiões. Seus benefícios, ou bônus demográficos, são distintos segundo os níveis sociais. Desse modo, a capacidade de a transição demográfica potencializar as transferências intergeracionais de recursos está intimamente associada à implementação de políticas que potencializem as transferências sociais desses mesmos recursos.
\end{abstract}

Palavras-chave: Transição demográfica. Bônus demográfico. Desigualdade social.

\section{Introdução}

Este artigo não tem a pretensão de superar os limites de um ensaio. O seu objetivo é combinar as exigências impostas pela imaginação analítica com a referência necessária às evidências empíricas, sem perder o fio condutor do rigor lógico. O tema - transição demográfica no Brasil - exige, pela sua relevância, mais do que rastrear dados, apelando, permanentemente, a desafios para sua compreensão. Se não bastasse a vereda de enigmas a serem decifrados pela imaginação criadora, a transição demográfica no Brasil ainda reserva aos que a analisam a oportunidade de se defrontarem com caminhos sociais alternativos postos por ela. Ao rigor lógico, indispensável,

\footnotetext{
* Professor do Centro de Desenvolvimento e Planejamento Regional (Cedeplar) e do Departamento de Demografia da UFMG. O autor agradece a leitura atenta do seu colega José Alberto Magno de Carvalho, porém as idéias nele contidas são de inteira responsabilidade do autor. Este artigo não poderia ser escrito sem a colaboração de Camila do Couto Seixas na elaboração dos dados. Agradeço, também, a Cíntia Simões Agostinho pela organização da base de dados.
} 
ela acrescenta uma demanda normativa: como melhor aproveitá-la, na perspectiva de melhorar as condições sociais da maioria da população brasileira. Questão decisiva para este ensaio, pois a transição demográfica no Brasil poderia contribuir tanto para reduzir as desigualdades sociais quanto para mantê-las ou, até, exacerbá-las. Evidências empíricas, imaginação analítica e, conseqüentemente, análise das políticas sociais são os objetivos buscados por este ensaio na compreensão da transição demográfica no Brasil. Certamente, ficará aquém deles. Contudo, procurá-los adequadamente já será um êxito deste ensaio.

A transição demográfica é um dos fenômenos estruturais mais importantes que tem marcado a economia e a sociedade brasileiras desde a segunda metade do século passado. Trata-se de um fenômeno caracterizado pela sua universalidade, mas fortemente condicionado pelas condições históricas em que se realiza nos diferentes países. Sua diferença em relação aos países desenvolvidos e sua semelhança com os outros em desenvolvimento não esgotam a sua originalidade.

A originalidade da transição demográfica no Brasil está definida pelas particularidades históricas onde ela se insere, permeadas pelos fortes desequilíbrios regionais e sociais. Nessa perspectiva ela é única, enquanto um processo global que atinge toda a sociedade brasileira, mas, ao mesmo tempo, múltipla, pois se manifesta diferentemente segundo as diversidades regionais e, principalmente, sociais.

Inserida e intensamente articulada a esse contexto de desenvolvimento desequilibrado, a transição demográfica não é autônoma. Ela é um processo social que não se resume aos efeitos combinados das variáveis estritamente demográficas. Pelo contrário, imersa nas profundas mudanças sociais e econômicas pelas quais tem passado o Brasil, é, simultaneamente, uma de suas causas e um de seus efeitos. Como tal está longe de ser considerada neutra: pode tanto criar possibilidades demográficas que potencializem o crescimento da economia, aumentando o bem-estar social, quanto potencializar as adversidades econômicas e sociais, ampliando as graves desigualdades sociais que marcam a sociedade brasileira.

Se não há neutralidade, não se pode fugir de uma abordagem normativa da transição demográfica. Em outras palavras, como ela pode favorecer caminhos sociais diferenciados, sua análise não deve se abster dessa questão decisiva. Seria um grande equívoco reduzir as preocupações analíticas e políticas com a transição demográfica às suas lógicas conseqüências atuariais, muitas vezes resumidas às meras implicações sobre as relações custos-benefícios. Desse modo, a análise, bem como suas inevitáveis conseqüências políticas, ficaria restringida às sugestões sobre a "racionalidade dos meios", desconsiderando os objetivos sociais a serem alcançados. Esses, inevitavelmente, obedecem a uma moldura normativa da transição que ilumina o projeto social preferido pelo analista.

Isso é fundamental, pois, se a transição não é neutra e pode favorecer conseqüências sociais diversas, ela depende de políticas que podem colocá-la nos trilhos que a levará a um destino ou outro. Trata-se de uma opção; não se está diante de uma fatalidade histórica, em que a lógica do mercado da economia contemporânea globalizada amarraria o destino da sociedade brasileira à sua rigorosa seletividade, traçando os limites para as políticas públicas. Pelo contrário, as possibilidades abertas pela transição demográfica devem significar o desafio de ultrapassar esses limites, ampliando os caminhos que podem levar à redução das desigualdades sociais.

A transição demográfica leva décadas. A princípio, isso coloca problemas diante da perspectiva temporal dos formuladores de políticas públicas, que normalmente planejam considerando um período muito inferior. Para os demógrafos, normalmente, meio século corresponde a médio prazo, mas, do ponto de vista da formulação de políticas, meio século é uma eternidade. É necessário mudar as atitudes dos formuladores de políticas, assim como dos demógrafos, na direção de serem compreendidas, articuladamente, as visões de curto, médio e longo prazos. Muitas vezes, 
tendências de longo prazo se manifestam de maneira aparentemente contraditória no curto e médio prazos. Um bom exemplo, e que será o objeto de análise neste artigo, é o crescimento populacional.

Apesar de levar décadas, a transição demográfica no Brasil tem sido acelerada, como em outros países em desenvolvimento, com um declínio rápido dos níveis de fecundidade e do ritmo de crescimento demográfico. Entretanto, como um processo recente, apesar de ter reduzido o ímpeto do crescimento populacional, ele ainda será expressivo nessa primeira metade do século XXI, com o grande ciclo de incrementos absolutos da população brasileira que se iniciou nos anos 70 do século passado.

Conseqüentemente, a transição da estrutura etária, ainda que tenha diminuído a proporção de jovens e aumentado a dos idosos, possibilitará que no final dessa década, em 2010, a população jovem tenha o seu maior tamanho absoluto. O crescimento da população em idade ativa (PIA), acompanhando a população total, ainda se manterá até 2040-2050. Isso, por um lado, pode ser um benefício, favorecendo as relações de dependência demográficas e, conseqüentemente, as transferências intergeracionais, quando o número de dependentes, jovens e idosos, em relação à PIA, será extremamente baixo, mas, por outro, se o crescimento da economia e as mudanças na regulação do mercado de trabalho não superarem seu comportamento recente, a proporção de desempregados e empregados na informalidade comprometerá as oportunidades demográficas.

Permeando as discussões sobre crescimento populacional e transição da estrutura etária, neste artigo, estão os agudos desequilíbrios sociais que afetam o Brasil, com a coexistência de diferentes etapas da transição demográfica, que caracterizam, como mencionado, a sua originalidade histórica.

\section{Crescimento populacional e a transição da estrutura etária}

A transição demográfica nos países em desenvolvimento, latino-americanos e asiáticos, tem sido muito mais acelerada do que naqueles desenvolvidos. No caso do Brasil, o declínio da fecundidade, após 1965, teve impacto, lógico, na redução do crescimento da população. Resultados recentes levaram a uma revisão, para baixo, das estimativas de fecundidade, pois a PNAD de 2004 indicou uma taxa de fecundidade total (TFT) de 2,1 filhos por mulher, ou seja, no nível de reposição da população (IBGE, 2006). O horizonte da fecundidade futura para o IBGE, considerando a TFT de 2030 como tendência, passou de 1,92 para 1,59 filho.

Esses dados levariam a uma revisão das projeções da população para o século XXI, o que ainda não foi realizado. Portanto, as projeções aqui utilizadas, a partir da fonte oficial, podem ser consideradas conservadoras. Segundo esses dados, alcançando uma fecundidade de 2,1 filhos por mulher, entre 2010 e 2020, a população brasileira chegaria à situação estacionária em torno de 2063, quando começaria a diminuir em termos absolutos. Tudo indica, com a revisão do IBGE, que o Brasil poderia alcançar uma taxa de crescimento zero entre 2045 e 2055(IBGE, 2006).

Não obstante, ainda devemos esperar um crescimento expressivo da população brasileira nas próximas décadas, em razão dos efeitos da fecundidade passada sobre a estrutura etária da população, marcada por uma grande proporção de mulheres em idade reprodutiva, o que favorece o crescimento populacional, a despeito dos baixos níveis de fecundidade atualmente predominantes. As projeções indicam para 2050 que o tamanho da população brasileira será de 253 milhões de habitantes, a quinta maior do planeta, inferior apenas às da Índia, China, EUA e Indonésia.

Haveria, então, um acréscimo de 90 milhões de habitantes à população brasileira nessa primeira metade do século XXI, o equivalente a 2,5 vezes a população da Argentina em 2005, ou seja, 18 milhões de habitantes por década, em média. Não se trata de se assombrar com a possibilidade de uma explosão demográfica, mas o crescimento populacional será, todavia, bastante expressivo (Gráfico 1). 


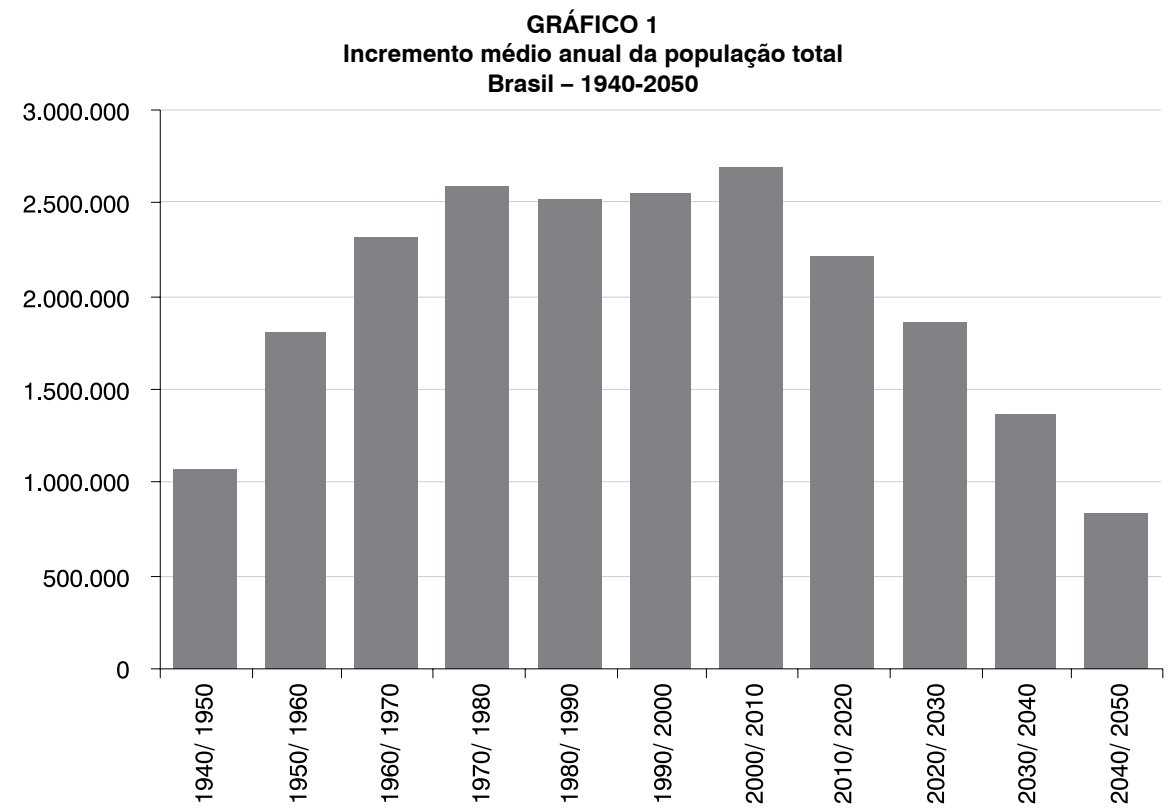

Fonte: IBGE/Diretoria de Pesquisas. Coordenação de População e Indicadores Sociais. Gerência de Estudos e Análises da Dinâmica Demográfica, 2004. Censos Demográficos de 1940, 1950, 1960 e 1970.

Da década de 70 até a atual, que se encerrará em 2010, a população brasileira ainda encontra-se em seu grande ciclo de crescimento absoluto, com aumentos médios anuais superiores a 2,5 milhões de habitantes. Na próxima década, os incrementos ainda serão superiores a dois milhões. No entanto, como as taxas de crescimento vêm se reduzindo neste mesmo período, espera-se que, na última década dessa primeira metade de século, ou seja, entre 2040 e 2050, o incremento médio anual seja inferior a um milhão de habitantes, segundo as estimativas do IBGE.

Em síntese, entre 2005, quando a taxa de fecundidade total brasileira atingiu 2,1 filhos por mulher - nível necessário e suficiente para se alcançar um crescimento demográfico sustentado nulo, no longo prazo - e o período em que se constatará o crescimento verdadeiramente nulo da população brasileira, serão necessários pelo menos 40 anos. Estes resultados remetem a uma primeira grande questão a ser considerada na formulação de políticas públicas: devido ao ritmo diferenciado de crescimento dos diversos grupos sociais, a probabilidade maior é que a maioria dos nascidos na primeira metade desse século seja pobre.

Tomando-se como indicador da fecundidade a relação entre crianças de zero a quatro anos e as mulheres entre 15 e 39 anos, essas suas diferenças sociais podem ser bem observadas (Gráfico 2). Ainda que a diferença entre os valores para a população mais pobre - renda domiciliar per capita inferior a um salário mínimo -, nos dois últimos censos, seja inexpressiva e tenha se reduzido, ela é muito significativa quando se consideram os valores extremos da distribuição de renda.

Portanto, não é surpreendente que a distribuição da população brasileira, segundo a renda domiciliar per capita, revele uma profunda desigualdade social (Tabela 1). Evidentemente, essa distribuição é função não só dos diferenciais de fecundidade, mas, também, da mobilidade social entre os diferentes estratos. A rigidez estrutural da sociedade brasileira não é favorável à mobilidade social, cujas possibilidades têm ficado, em grande parte, nos últimos tempos, na dependência das políticas públicas de transferência de renda (BRITO, 2007). 
GRÁFICO 2

Quociente entre a população de 0 a 4 anos e a população feminina de 15 a 39 anos, segundo renda domiciliar per capita (em salários mínimos)

Brasil - 1980-2000

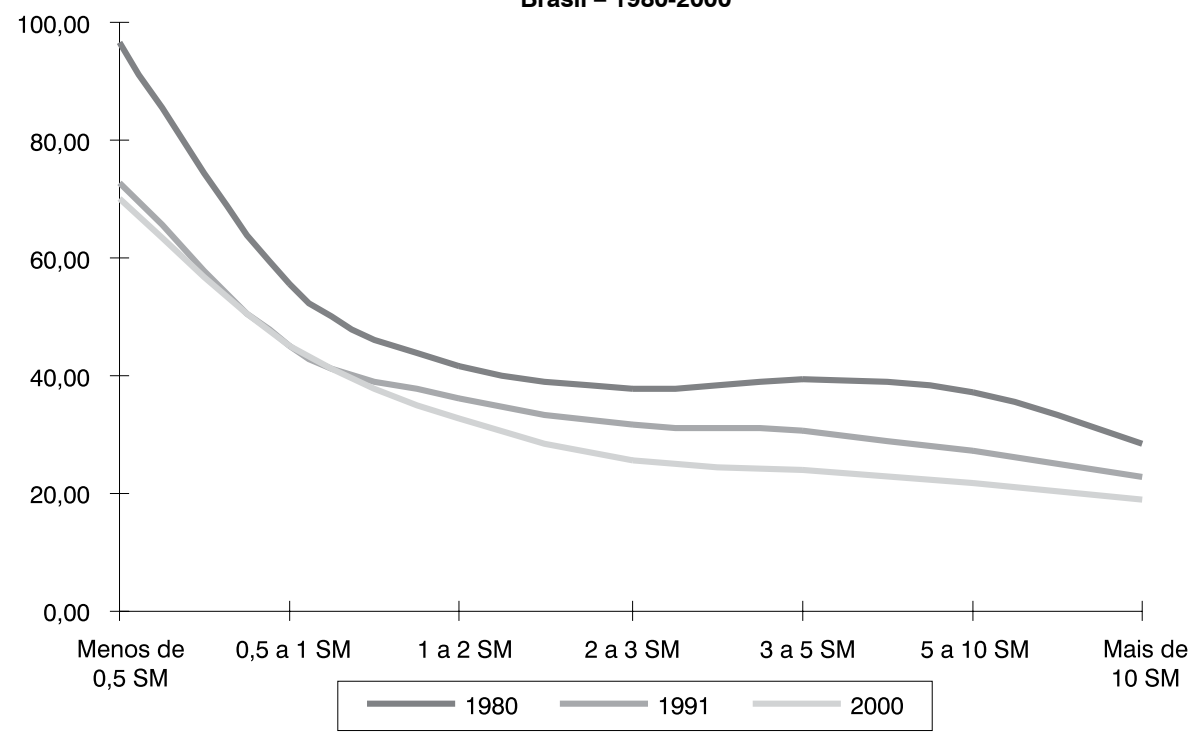

Fonte: IBGE. Censos Demográficos de 1980, 1991 e 2000.

TABELA 1

População total, segundo renda domiciliar per capita

Brasil - 1980-2000

\begin{tabular}{lrrr}
\hline Renda domiciliar per capita (em salários mínimos) & \multicolumn{1}{c}{$\mathbf{1 9 8 0}$} & $\mathbf{1 9 9 1}$ & $\mathbf{2 0 0 0}$ \\
\hline Até 0,5 SM & 57.711 .820 & 70.332 .627 & 53.218 .960 \\
De 0,5 a 1 SM & 26.407 .465 & 30.702 .893 & 39.361 .466 \\
De 1 a 2 SM & 17.159 .860 & 21.598 .045 & 36.864 .377 \\
De 2 a 3 SM & 5.767 .600 & 7.610 .639 & 13.941 .868 \\
De 3 a 5 SM & 4.453 .430 & 5.656 .629 & 11.814 .966 \\
De 5 a 10 SM & 2.595 .165 & 3.464 .631 & 8.604 .410 \\
Mais de 10 SM & 898.800 & 1.430 .408 & 4.826 .407 \\
Total & $\mathbf{1 1 5 . 0 6 0 . 5 2 0}$ & $\mathbf{1 4 0 . 7 9 9 . 8 3 4}$ & $\mathbf{1 6 8 . 6 3 8 . 2 0 1}$ \\
\hline
\end{tabular}

Fonte: IBGE, Censos Demográficos de 1980, 1991 e 2000.

Não há dúvida de que qualquer compromisso com a redução das desigualdades sociais passa, necessariamente, por reforçar na agenda política a necessidade de ações visando o apoio à população mais pobre, para que tenha condições de regular sua fecundidade, pois é este o segmento social com menos informação e acesso à contracepção. Para ter o exercício de sua cidadania plena, as mulheres, em geral, e as mais pobres, em particular, devem ter acesso às informações e aos meios de regulação da sua fecundidade, para que possam decidir, segundo seus interesses, o número adequado de filhos. Evidentemente, não é uma solução que ultrapasse seus próprios limites, como muitos ainda acreditam, servindo como único remédio para as mazelas sociais. Contudo, não se pode separar a reprodução estritamente demográfica da população da sua reprodução social. Elas estão intimamente articuladas. No que se refere ao segmento pobre, então, esta associação não pode ser desprezada quando se pensa em políticas sociais. Mesmo com declínio da sua fecundidade, a dimensão dessa população é tão grande que qualquer incremento torna-se significativo. Pensando na situação extrema, otimista do ponto de vista demográfico, até mesmo no longo 
prazo, quando a taxa de crescimento da população pobre alcançasse seu nível de reprodução, se as condições sociais atuais se mantivessem, ela estaria apenas se reproduzindo, mas como uma população pobre (BRITO, 2006).

No que se refere à transição demográfica, mais importante ainda que a população pobre, em seu conjunto, são os jovens pobres. O peso relativo do total do segmento jovem - aquele abaixo de 15 anos - tem diminuído, em função do declínio da fecundidade. Essa redução teria sido ainda maior se não tivesse ocorrido queda significativa da mortalidade infantil. Entre 1970 e 2000, a mortalidade infantil passou de 115 para 30 óbitos de crianças com menos de um ano por 1.000 nascidas vivas (IBGE, 2006). A queda da proporção de jovens acontece em ritmo mais acelerado do que o aumento da de idosos, pois a substituição de jovens por idosos é mediatizada pelo crescimento da população adulta. Contudo, a visão exclusiva do decréscimo proporcional dos jovens pode obscurecer a compreensão da sua importância em termos absolutos, fundamental para a definição das políticas públicas (Gráfico 3). Em 2010, a população jovem alcançará seu maior volume em toda a história brasileira (53 milhões), permanecendo praticamente constante entre $1990 \mathrm{e}$ 2030, com oscilação de valores ligeiramente superiores a 50 milhões de indivíduos.

No caso dos serviços relativos à população jovem, como os educacionais, a redução do ritmo de crescimento da demanda pode favorecer a universalização da cobertura e a melhoria da qualidade do ensino. Além disso, seria menos onerosa a ampliação do tempo durante o qual os jovens deverão estar inseridos no sistema escolar, facilitando, por exemplo, a implementação da escola em tempo integral. Entretanto, do ponto de vista das políticas públicas, não pode ser desconsiderado que a população-alvo, os jovens, terá na próxima década o seu maior tamanho absoluto. Atualmente, há consenso quanto à necessidade de políticas que garantam $a$ universalização efetiva do atendimento dos ensinos fundamental e médio. $O$ ensino fundamental, exclusivamente, em nada garante a inclusão social, via mercado de trabalho, cujos requisitos para a entrada tornam-se

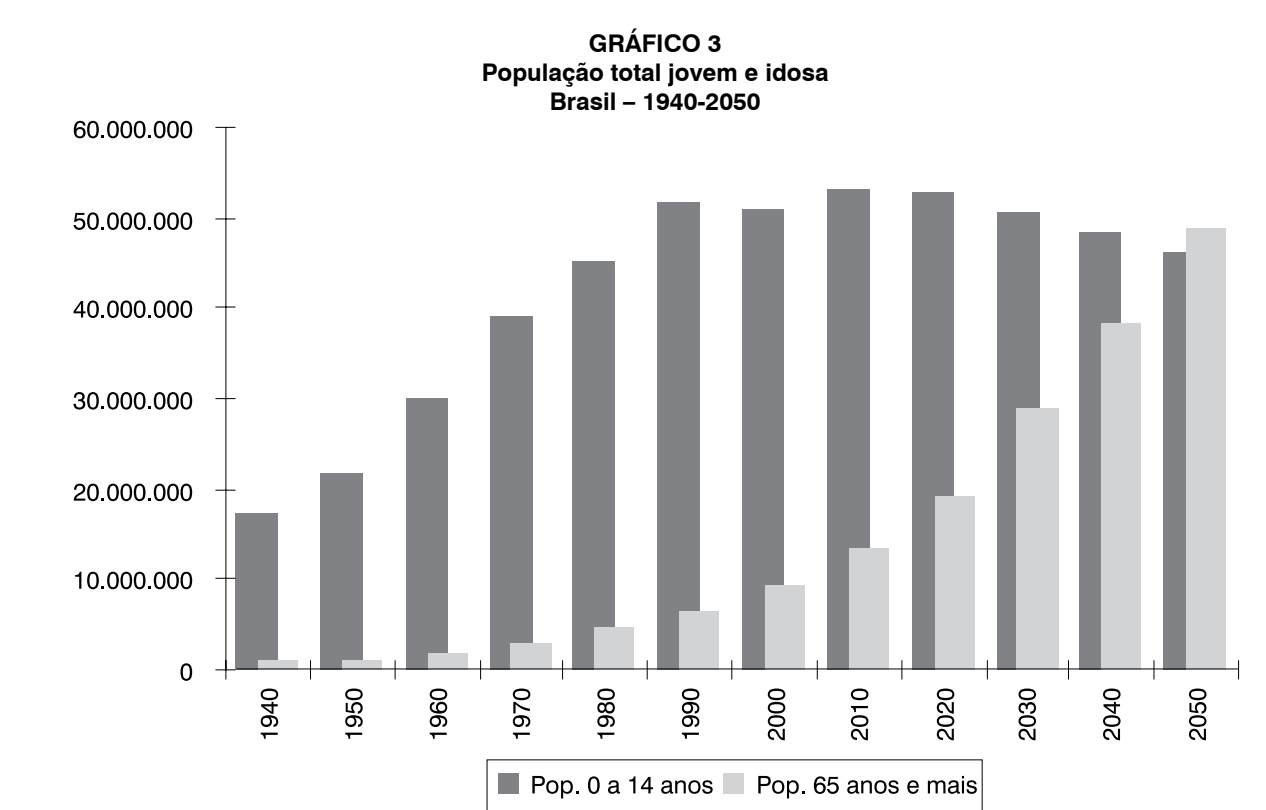

Fonte: IBGE/Diretoria de Pesquisas. Coordenação de População e Indicadores Sociais. Gerência de Estudos e Análises da Dinâmica Demográfica, 2004. Censos Demográficos de 1940, 1950, 1960 e 1970. 
cada vez mais rigorosos. O ensino médio assume uma importância fundamental, principalmente o profissionalizante.

O grupo etário que constituiria essa demanda potencial para os ensinos fundamental e médio, ou seja, a população entre 5 e 19 anos, ainda crescerá, lentamente, até 2020, quando alcançará seu tamanho máximo, cerca de 53,5 milhões de pessoas (Gráfico 4). $O$ atendimento ao ensino médio passa a ser o grande gargalo da educação brasileira, não somente pela pressão demográfica, mas, também, pelo aumento significativo da população que completa o ensino fundamental e deseja continuar os estudos. $O$ ensino médio enfrentará, dessa forma, dois grandes desafios: atender a toda a demanda e aumentar a qualidade do ensino, sem se beneficiar, no curto e médio prazos, com a redução da população-alvo.

Torna-se evidente que os benefícios demográficos, no que se refere à demanda pelo ensino, ocorrem devido ao menor ritmo de crescimento do tamanho da populaçãoalvo. O passivo demográfico, determinado pelo longo período de fecundidade alta, ainda proporcionará à população jovem o seu maior tamanho absoluto na próxima década. Entretanto, incrementos menores ou negativos significam, realmente, um alívio na pressão sobre o crescimento da oferta da capacidade instalada para os serviços educacionais, o que deve ser aproveitado, como um benefício, pelas políticas públicas.

No entanto, a questão não é eleger uma nova panacéia, em que as condições da estrutura etária garantiriam o êxito das políticas educacionais. A situação demográfica favorável, por si só, pouco significará se não for aproveitada com eficiência, quanto aos meios, e com objetivo social de ampliar, pela qualidade, a capacidade de mobilidade social da maioria da população pobre, reduzindo, desse modo, as desigualdades sociais.

No caso brasileiro, os benefícios demográficos estão fortemente condicionados pela gravidade da situação social. Isso fica nítido quando se constata que a maioria da população jovem, no Brasil, é pobre. Nos três últimos censos, a porcentagem de jovens de família com renda domiciliar per capita inferior a um salário mínimo tem diminuído, mas situava-se, em 2000, acima

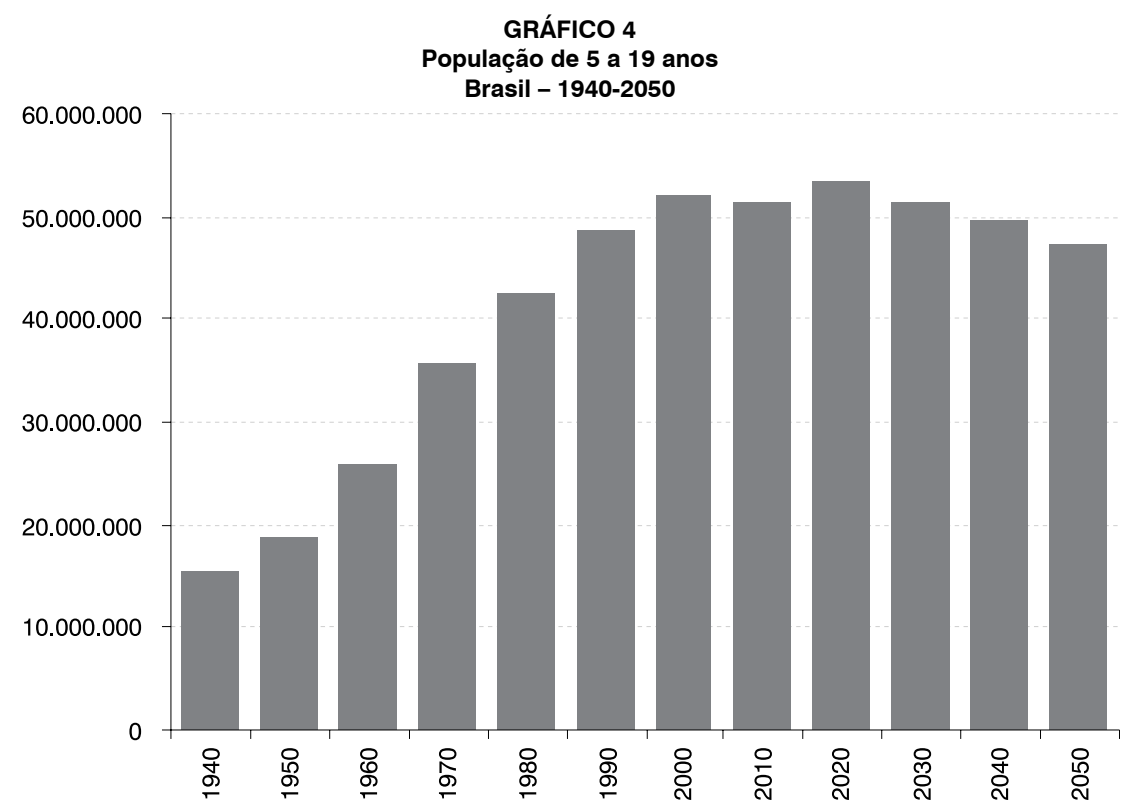

Fonte: IBGE/Diretoria de Pesquisas. Coordenação de População e Indicadores Sociais. Gerência de Estudos e Análises da Dinâmica Demográfica, 2004. Censos Demográficos de 1940, 1950, 1960 e 1970. 
TABELA 2

População de 0 a 14 anos, segundo renda domiciliar per capita Brasil - 1980-2000

\begin{tabular}{lrrr}
\hline Renda domiciliar per capita (em salários mínimos) & $\mathbf{1 9 8 0}$ & $\mathbf{1 9 9 1}$ & $\mathbf{2 0 0 0}$ \\
\hline Menos de 0,5 SM & 28.080 .785 & 30.172 .245 & 22.772 .911 \\
0,5 a 1 SM & 8.936 .140 & 9.581 .004 & 12.037 .152 \\
1 a 2 SM & 4.495 .090 & 5.639 .995 & 8.440 .278 \\
2 a 3 SM & 1.316 .995 & 1.802 .191 & 2.692 .267 \\
3 a 5 SM & 1.012 .750 & 1.273 .524 & 2.164 .792 \\
5 a 10 SM & 548.195 & 701.781 & 1.431 .766 \\
Mais de 10 SM & 137.115 & 232.749 & 638.584 \\
Total & $\mathbf{4 4 . 5 3 8 . 0 2 0}$ & $\mathbf{4 9 . 4 0 4 . 6 9 1}$ & $\mathbf{5 0 . 1 7 9 . 4 7 1}$ \\
\hline
\end{tabular}

Fonte: IBGE, Censos Demográficos de 1980, 1991 e 2000.

de $70 \%$, mais de 32 milhões de pessoas. No nível mais baixo de pobreza ainda se encontravam $45 \%$, cerca de 23 milhões de jovens.

Os investimentos maciços em educação, inclusive a escola integral com formação técnica até o ensino médio, implicam uma grande vontade política. Como foi mencionado, o público-alvo ainda se manterá muito alto nas duas próximas décadas. Numa hipótese pessimista, se for mantida, em 2010, a mesma proporção de jovens pobres de 2000, ou seja, aqueles com renda domiciliar inferior a meio salário mínimo, eles seriam mais de 24 milhões, quase a metade de todos os jovens.

Por outro lado, a população idosa tem apresentado uma velocidade no seu incremento absoluto maior do que a da população total, aumentando, conseqüentemente, sua participação relativa. Associese, a esse fenômeno do envelhecimento da população, o aumento da sua longevidade, bem traduzida pelos ganhos na esperança de vida ao nascer, que já alcançava 72,1 anos em 2005. Deve-se lembrar que os países desenvolvidos, quando estavam na fase atual da transição demográfica brasileira, tinham não apenas uma economia com crescimento sustentado, mas também um Estado do Bem-Estar Social consolidado. O Brasil, ao contrário, não tem registrado taxas satisfatórias de crescimento da sua economia, assim como se apressa em reformar seu sistema de seguridade social, que ainda se encontra a uma enorme distância da experiência dos países desenvolvidos.

O envelhecimento da população, ou seja, o aumento da proporção de pessoas com 65 anos de idade ou mais é uma característica marcante da transição da estrutura etária brasileira. Essa proporção será de $7,0 \%$ em 2010, pouco mais de 13 milhões de idosos. Comparativamente, naquele ano, um grupo com 40 milhões de pessoas a menos do que os jovens.

Durante a primeira década deste século, a população idosa tem aumentado, em média, 387 mil pessoas por ano. Mas, nos últimos dez anos da primeira metade do século, estima-se que esse crescimento corresponderá a mais de um milhão de indivíduos por ano. Em 2050, a população idosa será cerca de 3,7 vezes maior do que a de 2000, próxima de 49 milhões. As conseqüências deste grande incremento serão enormes, exigindo uma redefinição de todas as políticas públicas voltadas para esse segmento populacional.

A questão mais importante para as políticas públicas, de fato, é a situação social dos idosos. A proporção deles no estrato mais pobre da população tinha aumentado entre 1980 e 1991, mas teve uma grande redução entre os dois últimos censos. Em 2000,12\% da população idosa possuía renda domiciliar per capita inferior a meio salário mínimo, ou seja, uma situação inequívoca de pobreza. Ampliando a faixa de pobreza até um salário mínimo, tem-se um terço dos idosos, cerca de 3,5 milhões.

Há uma relação positiva entre a proporção de idosos e o nível de renda, quando se considera cada um dos grupos. Ela aumenta, certamente, devido a uma maior longevidade e menor fecundidade dos grupos economicamente mais favorecidos da população. O segmanto com mais de dez 
TABELA 3

População de 65 anos e mais, segundo renda domiciliar per capita Brasil - 1980-2000

\begin{tabular}{lrrr}
\hline Renda domiciliar per capita (em salários mínimos) & $\mathbf{1 9 8 0}$ & $\mathbf{1 9 9 1}$ & $\mathbf{2 0 0 0}$ \\
\hline Menos de 0,5 SM & 1.939 .910 & 3.116 .687 & 1.189 .290 \\
0,5 a 1 SM & 1.212 .300 & 1.470 .084 & 2.341 .862 \\
1 a 2 SM & 712.550 & 1.072 .662 & 3.236 .355 \\
2 a 3 SM & 272.240 & 399.974 & 997.202 \\
3 a 5 SM & 235.685 & 323.536 & 857.467 \\
5 a 10 SM & 159.145 & 230.618 & 689.668 \\
Mais de 10 SM & 83.530 & 128.438 & 483.751 \\
Total & $\mathbf{4 . 6 1 9 . 2 7 0}$ & $\mathbf{6 . 7 4 2 . 2 2 5}$ & $\mathbf{9 . 7 9 5 . 7 7 5}$ \\
\hline
\end{tabular}

Fonte: IBGE. Censos Demográficos de 1980, 1991 e 2000.

salários mínimos de renda per capita familiar, em 2000 , tinha $10 \%$ de idosos, enquanto os mais pobres possuíam apenas $2 \%$.

O fato mais notável, entretanto, quando se observa a distribuição de renda da população idosa, na última década, é a diminuição, tanto em termos absolutos quanto relativos, dos idosos mais pobres. Por outro lado, aumentaram aqueles com renda domiciliar entre meio e um salário mínimo e, fundamentalmente, o grupo entre um e dois salários mínimos, em que se situavam, em $2000,57 \%$ dos idosos, contra $38 \%$ em 1991. Essas mudanças, provavelmente, devem ter sido causadas pelas políticas de transferência de renda definidas pela Constituição de 1988. Boa parte dessa parcela da população tem sido objeto de políticas de transferência de renda, como a aposentadoria rural e o Benefício de Prestação Continuada (BPC).

A título de exemplo, tome-se o Benefício de Prestação Continuada (BPC). Seria razoável esperar que o volume de recursos a serem dispensados nesse programa de transferência de renda varie em proporção muito semelhante àquela da população idosa (CEDEPLAR/MDS, 2006). Por se tratar de transferências puras, o BPC não envolve contrapartida por parte dos beneficiários, mas sim recursos orçamentários. Em outras palavras, esse benefício é financiado por recursos fiscais pagos por outros segmentos sociais. A continuidade das políticas de transferência de renda deve ser equacionada, politicamente, no contexto de um projeto fiscal - fundamentalmente social - de transferência de renda favorável aos segmentos mais pobres da população. Não se trata, no caso brasileiro, de uma equação de fácil solução. Todavia, não há como fugir às suas incógnitas, pois, fazendo um mero exercício, os $57 \%$ de idosos (5,6 milhões) que em 2000 podem estar recebendo benefícios dos programas de transferência de renda serão, em 2050, segundo estimativas do IBGE, 28 milhões. Sendo realista, a situação social de parte da população idosa do Brasil será insustentável no futuro, se continuar a depender, como agora, de transferências maciças de renda originárias do orçamento. Os contornos dessa situação ficam ainda mais complexos quando se considera que a maioria dos jovens pobres, hoje, poderá ser os idosos pobres de amanhã.

Desse modo, ainda que aparentemente possa parecer contraditório no curto prazo, pois são segmentos etários com demandas competitivas de receitas públicas, não é possível pensar as políticas para os idosos, no médio e longo prazos, separadas das políticas para os jovens. Será decisivo, para equacionar a questão dos idosos, uma rigorosa política de investimentos no curto prazo na população jovem pobre, com o objetivo não só de garantir sua sobrevivência hoje, como pobre, mas, principalmente, que crie condições para sua mobilidade social, possibilitando sua definitiva inclusão social, no futuro.

Por outro lado, o sistema de previdência social, no qual, em princípio, haveria uma contrapartida adequada da parte dos futuros beneficiários, precisa se compatibilizar com o padrão demográfico emergente. A situação demográfica é favorável, o número de contribuintes potenciais, em 2010, é quase dez vezes maior do que o de idosos. A dificuldade, então, não se encontra, neste momento, nas relações intergeracionais, 


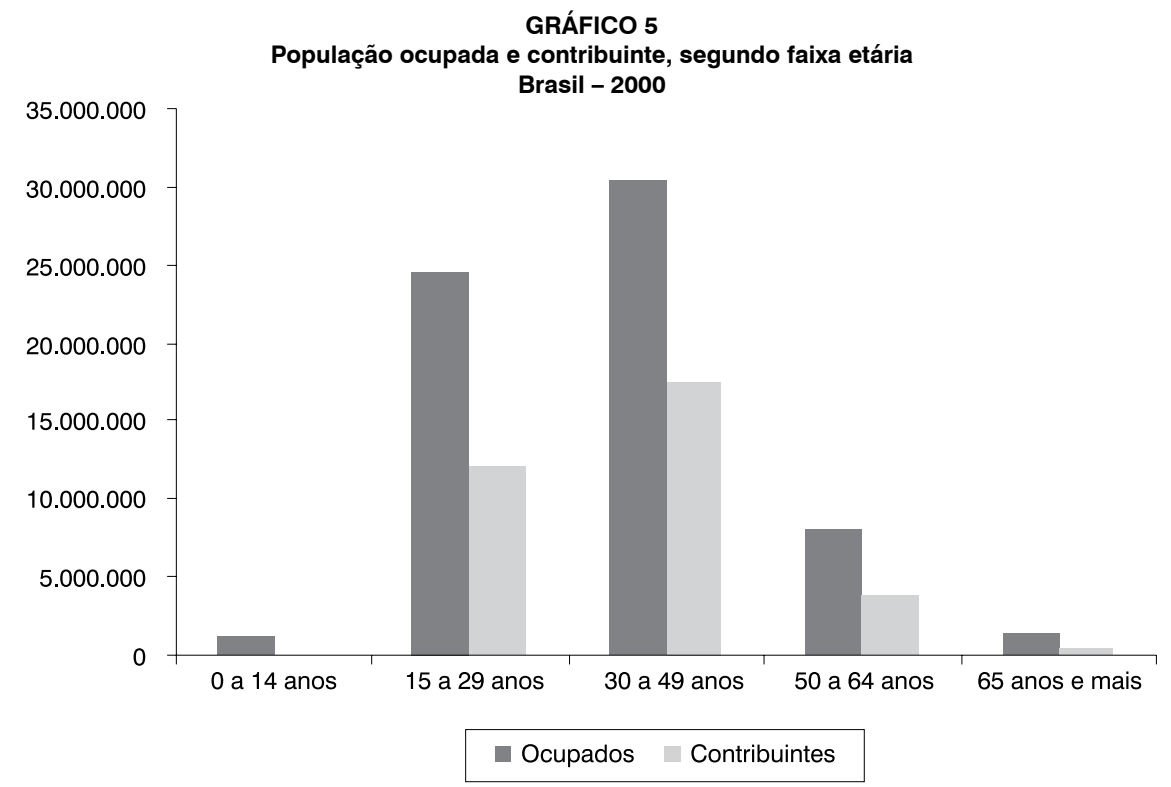

Fonte: IBGE. Censo Demográfico de 2000.

mas sim na maioria da PIA que não contribui, gerando graves problemas para o seu financiamento.

O Censo de 2000 mostra uma relação entre população ocupada e população contribuinte muito desfavorável à política previdenciária: praticamente, a metade dos ocupados não contribuía para a Previdência (Gráfico 5).

O cenário para a definição das políticas de previdência social, em particular, e da seguridade social, em geral, não pode deixar de levar em conta quem são os idosos hoje e como serão no futuro, do ponto de vista da sua renda. Atualmente, a dimensão absoluta da população idosa, vis-à-vis a da população em idade ativa, ainda não é tão relevante como será no futuro e, só por isso, a situação dos idosos ainda pode ser minimizada pelas políticas de transferência de renda definidas pela Constituição. Já a situação futura dependerá das possibilidades criadas pelo crescimento da economia, principalmente da geração de mais empregos e ocupações que aumentem o número de contribuintes, somando-se, como mencionado, as políticas públicas referentes aos jovens pobres, que devem ser objetivo prioritário do Estado. Caso isso não ocorra agora, a situação previdenciária ficará comprometida, pois, no médio prazo, provavelmente, haverá maior proporção de trabalhadores não-contribuintes e, no longo prazo, mais dependentes de programas de transferência de renda.

Equacionar o sistema de previdência social, sem que o país tenha alcançado os primeiros degraus de um Estado do BemEstar Social, é um desafio para as políticas que visem aumentar a justiça social e reduzir as desigualdades sociais, sem as quais as oportunidades demográficas serão desperdiçadas. Deve-se sublinhar, novamente, que, apesar de as implicações da transição demográfica sobre o sistema previdenciário serem observáveis, elas ainda estão distantes de expressar uma das principais causas da sua crise, ao contrário da situação atual dos países desenvolvidos.

Correntemente, enquanto se aumenta o peso relativo dos idosos, também cresce a população em idade ativa, de quem se espera, pela produção, poupança e investimentos, que seja a fonte de transferência de renda para os idosos, pelo menos teoricamente (TURRA; QUEIROZ, 2005). 


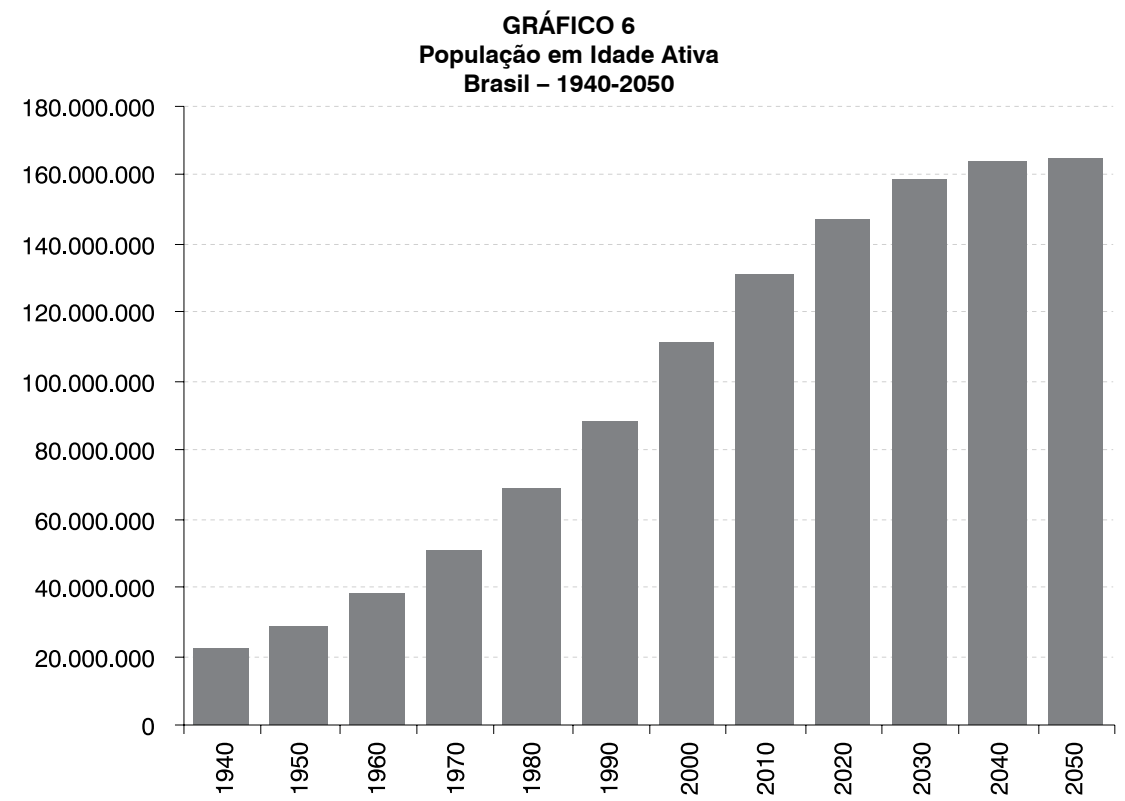

Fonte: IBGE/Diretoria de Pesquisas. Coordenação de População e Indicadores Sociais. Gerência de Estudos e Análises da Dinâmica Demográfica, 2004. Censos Demográficos de 1940, 1950, 1960 e 1970.

Entre 1950 e 2000, foram acrescentados 88 milhões de pessoas ao seu contingente populacional. O passivo demográfico, determinado pelo longo período de fecundidade alta, ainda irá incorporar à PIA cerca de 54 milhões de pessoas entre 2000 e 2050 (Gráfico 6).

O Brasil está muito distante da realidade dos países desenvolvidos que, desde o final da Segunda Guerra Mundial, precisam suprir parte das suas necessidades de mãode-obra através da migração internacional. Pelo contrário, desde 1980, o país passou a transferir população para nutrir o mercado de trabalho internacional. Entretanto, essa emigração é, relativamente, pouco expressiva, insuficiente para reduzir a pressão sobre a oferta de empregos. Contudo, uma nova corrente emigratória começa a se estabelecer, transferindo para os países desenvolvidos mão-de-obra qualificada, com educação superior ou mais, visando suprir as necessidades daquelas economias, cujos mercados de trabalho, cada vez mais exigentes quanto à formação profissional, não têm a quantidade de oferta de força de trabalho demandada. Embutida nessa emigração, transfere-se para os países desenvolvidos investimentos maciços em educação.

Voltando ao crescimento da PIA e considerando a população de 15 a 24 anos aquela que potencialmente poderia se incorporar ao mercado de trabalho no decênio, suas estimativas para um futuro próximo não podem, propriamente, ser entendidas como um benefício demográfico. Seu incremento decenal tem sido negativo nesta primeira década do século XXI, mas será positivo entre 2010 e 2030. Novamente, o passivo demográfico possibilitará que, de 2000 a 2050, a população jovem, potencialmente demandante de um lugar no mercado de trabalho, varie em tamanho absoluto, em cada uma das décadas, entre 32 e 34,7 milhões. Números extremamente grandes, distantes de aliviar a economia de uma grande necessidade de geração de emprego.

Simultaneamente à expressiva incorporação de mão-de-obra jovem, a população em idade ativa ficará mais velha, ainda que gradualmente, dentro do processo geral de envelhecimento da população brasileira. Durante a primeira metade do século XXI, a idade média da PIA aumentará em sete anos, passando de 30 , em 2000 , para 37 


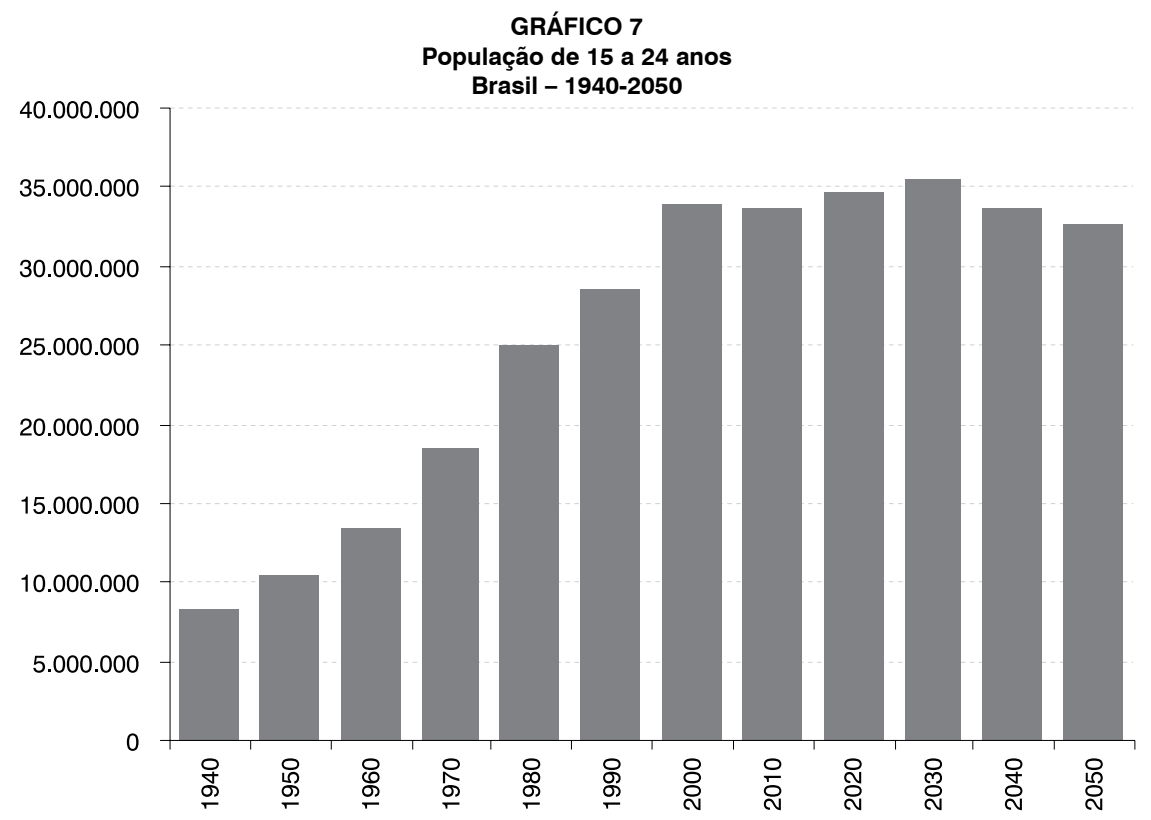

Fonte: IBGE/Diretoria de Pesquisas. Coordenação de População e Indicadores Sociais. Gerência de Estudos e Análises da Dinâmica Demográfica, 2004. Censos Demográficos de 1940, 1950, 1960 e 1970.

GRÁFICO 8

Incremento decenal da população em idade ativa e dos dependentes (jovens e idosos)

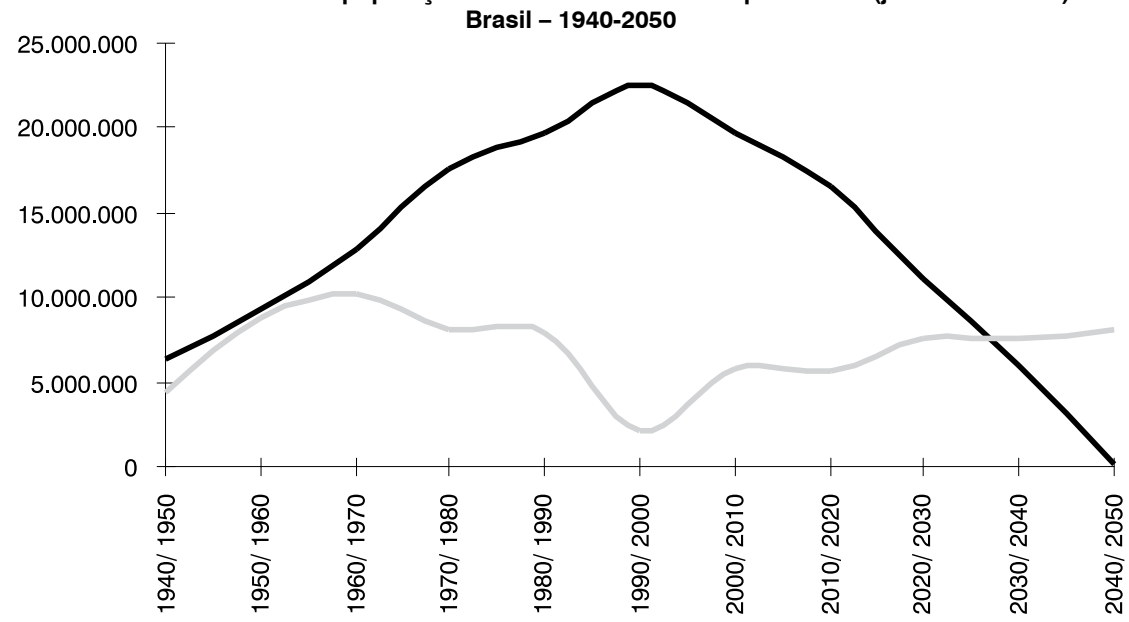

\section{$\longrightarrow$ PIA dependentes}

Fonte: IBGE/Diretoria de Pesquisas. Coordenação de População e Indicadores Sociais. Gerência de Estudos e Análises da Dinâmica Demográfica, 2004. Censos Demográficos de 1940, 1950, 1960 e 1970.

anos, em 2050, bem abaixo do envelhecimento do total da população, que no mesmo período terá um acréscimo de 15 anos, passando de 25 para 40 anos (BRITO, 2007).
O aumento do tamanho absoluto e do peso relativo da população em idade ativa, em relação aos dependentes, jovens e idosos, do ponto de vista estritamente 
demográfico, pode ser considerado um fator positivo para a economia (Gráfico 8). Essa seria a população que, teoricamente, produz, poupa, investe e contribui com impostos e para a previdência social. Em outras palavras, o pressuposto é de que os jovens e os idosos, provavelmente, consumam mais do que produzem e a população em idade ativa produza mais do que consome. Isso, em tese, seria mais verdadeiro quanto mais envelhecida se torna a PIA (BLOOM; CANNING; SEVILLA, 2003).

Fala-se em tese porque, se as condições demográficas são favoráveis, elas são dependentes de políticas públicas que garantam a efetividade dos benefícios demográficos. Essas políticas deveriam proporcionar o emprego da mão-de-obra disponível com uma remuneração condizente, a sua regulação pela legislação trabalhista, uma política fiscal e previdenciária adequada, dentro de um contexto de crescimento da economia. Caso contrário, a abertura das janelas de oportunidades demográficas pode passar desapercebida e o crescimento da PIA não terá o retorno econômico e social desejado.

\section{As relações intergeracionais e os benefícios demográficos}

As razões de dependência demográfica partem do pressuposto, antes exposto, de que a população jovem, de 0 a 14 anos, e a idosa, de 65 anos e mais, podem ser con- sideradas dependentes da população em idade ativa, de 15 a 64 anos. Ainda que os limites etários dos diferentes grupos possam ser contestados como arbitrários, trata-se de uma aproximação razoável e reconhecida internacionalmente. A razão de dependência total (RDT) seria a proporção dos jovens e idosos em relação à PIA. Os dependentes, teoricamente, consumiriam mais do que produzem e a população adulta produziria mais do que consome. Essa seria a relação básica que expressa a transferência entre as gerações. A RDT pode ser desdobrada em seus componentes: a razão de dependência dos jovens (RDJ) e a dos idosos (RDI). A primeira seria a proporção dos jovens em relação à PIA e a segunda a dos idosos.

Até 1970 , antes do declínio acelerado e generalizado da fecundidade, a RDT tinha valores extremamente altos (Tabela 4). Em 1960, por exemplo, o seu valor era de $83 \%$, isto é, para cada 100 pessoas na PIA, havia 83 jovens e idosos, ou, mais especificamente, 78 jovens e cinco idosos. De fato, a grande "carga" para a PIA eram os jovens. Não se poderia esperar outra coisa de um país, naquele momento, com uma fecundidade alta e crescimento acelerado da população, que contava com 30 milhões de jovens e apenas 1,9 milhão de idosos. Um outro indicador das relações intergeracionais é o índice de idosos, isto é, o quociente entre o número de idosos e o de jovens. Em 1960, esse valor era de 6,4 idosos para cada 100 jovens, o que só confirma a situação da

TABELA 4

Razão de dependência total, de jovens e de idosos, índice de idosos e idade mediana Brasil - 1950-2050

\begin{tabular}{|c|c|c|c|c|c|}
\hline \multirow{2}{*}{ Período } & \multicolumn{3}{|c|}{ Razão de Dependência } & \multirow{2}{*}{ Índice de Idosos } & \multirow{2}{*}{ Idade Mediana } \\
\hline & Total & Jovens & Idosos & & \\
\hline 1950 & 79,06 & 74,7 & 4,36 & 5,83 & 19,2 \\
\hline 1960 & 82,95 & 77,95 & 5,0 & 6,41 & 18,6 \\
\hline 1970 & 82,33 & 76,6 & 5,73 & 7,48 & 18,6 \\
\hline 1980 & 73,04 & 66,1 & 6,94 & 10,49 & 20,3 \\
\hline 1990 & 65,81 & 58,58 & 7,23 & 12,34 & 22,5 \\
\hline 2000 & 54,37 & 45,97 & 8,41 & 18,28 & 25,3 \\
\hline 2010 & 50,69 & 40,59 & 10,1 & 24,88 & 28,5 \\
\hline 2020 & 48,79 & 35,8 & 12,99 & 36,28 & 31,9 \\
\hline 2030 & 50,15 & 31,93 & 18,22 & 57,08 & 34,7 \\
\hline 2040 & 52,96 & 29,58 & 23,39 & 79,08 & 37,6 \\
\hline 2050 & 57,87 & 28,15 & 29,72 & 105,56 & 40,3 \\
\hline
\end{tabular}

Fonte: IBGE/Diretoria de Pesquisas. Coordenação de População e Indicadores Sociais. Gerência de Estudos e Análises da Dinâmica Demográfica, 2004. Censos Demográficos de 1950, 1960 e 1970. 
população brasileira na época, jovem, com $50 \%$ da sua população com menos de 20 anos de idade. No final do século passado, a razão de dependência total já tinha baixado para $54 \%$, mesmo assim ainda mantendo um grande peso dos jovens.

Na primeira metade deste século, a RDT permanecerá entre $49 \%$ e $57 \%$, mudando, no entanto, profundamente sua composição. Enquanto em 2000 a razão de dependência dos jovens era quase seis vezes maior do que a dos idosos, em 2050, as duas razões de dependência serão praticamente iguais.

Os demógrafos têm chamado atenção para as oportunidades demográficas que poderiam ser usufruídas pela sociedade e economia, entre 2010 e 2030, em função, principalmente, do crescimento da PIA, acompanhado pela redução da razão de dependência total, que, nesse período, alcançará seus menores valores, em torno de $50 \%$, sendo que o peso relativo dos idosos ainda será bem menor do que o dos jovens. Ter-se-ia, para cada 100 pessoas em idade ativa, apenas 50 jovens e idosos, com preponderância dos jovens. Em outras palavras, as transferências intergeracionais seriam favorecidas pela relação de um por dois, ou seja, apenas uma pessoa dependente para cada duas potencialmente produtivas. No intervalo mais amplo, entre 2000 e 2040, as condições demográficas poderiam ser consideradas favoráveis: em 2000 , a RDT era de, aproximadamente, $54 \%$ e, em 2040 , seria de $53 \%$. Mesmo com uma razão de dependência total de $54 \%$ - seu maior valor - ter-se-ia 1,08 dependente para cada duas pessoas potencialmente produtivas. Situação plenamente satisfatória do ponto de vista da dependência demográfica.

Como se sabe, a definição da população em idade ativa é estritamente demográfica, o que não dispensaria um exercício com os dados do Censo de 2000, verificando quem são aqueles que estão ocupados ou não e, no caso da previdência social, quais são os ocupados que contribuem ou não, ou seja, aqueles que participam ou não do mercado de trabalho formal. Pode-se, desse modo, ter uma visão mais realista das razões de dependência e dos seus benefícios.

Para simplificar a análise dos ocupados e dos contribuintes, segundo a estrutura

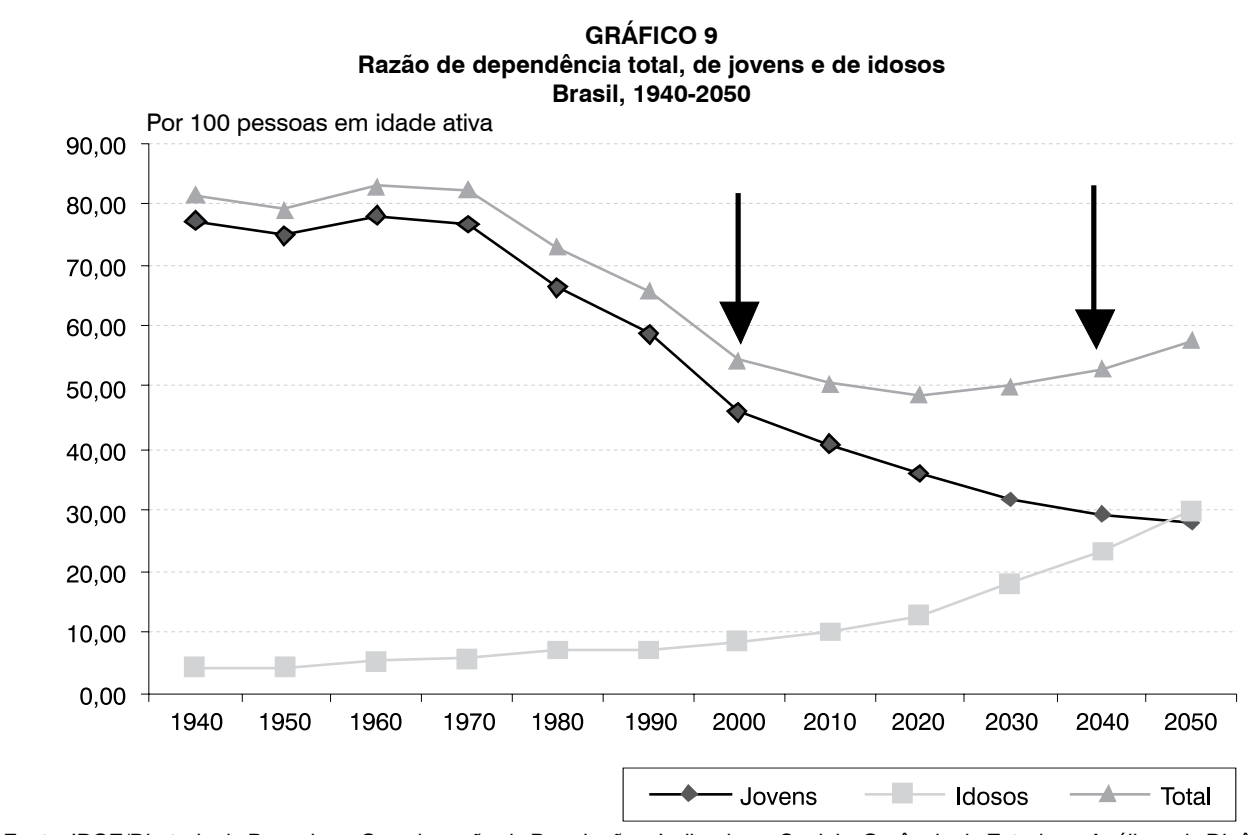

Fonte: IBGE/Diretoria de Pesquisas. Coordenação de População e Indicadores Sociais. Gerência de Estudos e Análises da Dinâmica Demográfica, 2004. Censos Demográficos de 1940, 1950, 1960 e 1970. 
etária, serão utilizados os três grandes grupos etários, os jovens, a população em idade ativa e os idosos. A PIA será subdividida em três faixas: 15 a 29 anos; 30 a 49 anos; e 50 a 64 anos.

A definição estritamente demográfica não está tão distante da realidade. Entre os ocupados, em 2000 , 96\% encontravam-se entre 15 e 64 anos, sendo o grupo modal o de 30-49 anos (Gráfico 10). As pessoas neste grupo, mais aquelas de 15-29 anos, os jovens da PIA, correspondiam a $84 \%$ dos ocupados. Apenas $4 \%$ estavam entre os grupos dependentes.

Considerando, ainda, a população ocupada em relação à não-ocupada, em termos absolutos, nota-se que os não-ocupados formam uma curva decrescente à medida que aumenta a idade (Gráfico 11). Na PIA, situavam-se 63 milhões de pessoas ocupadas. Este contingente, somado ao pequeno número dos ocupados nos grupos de jovens e idosos fora da PIA, perfaz um total de 66 milhões de pessoas ocupadas, no Brasil, em 2000.
Uma população em idade ativa, com essa dimensão, pode realmente constituir um grande benefício? Do ponto de vista estritamente demográfico não restariam dúvidas, pois as razões de dependência são contundentes. Pelo menos teoricamente, poderia ser considerado um dividendo demográfico (GUZMAN, 2006) Como na PIA está a maioria dos que trabalham, geram receita, em tese, produzem mais do que consomem e, ainda, transferem renda através de impostos e contribuições, não haveria como discordar. Esse dividendo, chamado de primeiro, por alguns, é considerado transitório, pois depende do comportamento favorável da razão de dependência. No caso brasileiro, pelo menos até 2040 , esse benefício poderia ser usufruído. Se esse benefício é considerado transitório, o chamado segundo dividendo seria permanente, já que depende do efeito combinado do envelhecimento e do aumento da longevidade. Populações mais envelhecidas e com maior expectativa de vida, tendência inexorável da transição demográfica, estariam mais

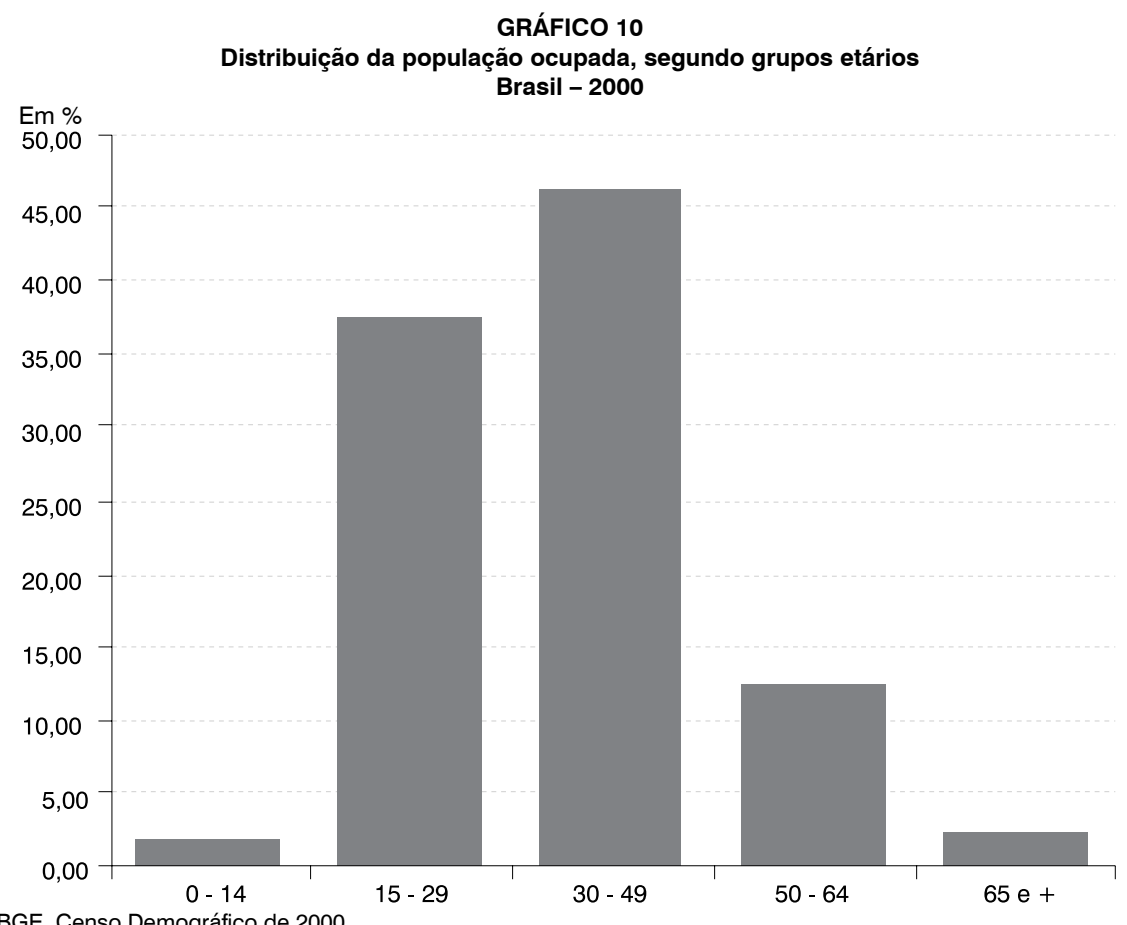

Fonte: IBGE. Censo Demográfico de 2000. 
propensas a gerar maior poupança e, por hipótese, aumentar o potencial de crescimento da economia e do bem-estar social (QUEIROZ; TURRA, 2006).

Entretanto, quando se considera a realidade da sociedade brasileira, em que o número de pessoas desocupadas é ainda muito grande, a razão de dependência demográfica pode não ser um indicador suficiente. Considerando uma razão de dependência mais restrita, quando se tomariam, em todas as idades, os não-ocupados como dependentes dos ocupados, a proporção dos dependentes fica muito maior: $161 \%$ em 2000, ou seja, para cada cem pessoas ocupadas, ter-se-iam 161 não-ocupadas, o que significa que a carga econômica daqueles que estão realmente ocupados é muito maior do que revela a razão de dependência estritamente demográfica.

Entre os ocupados, a população contribuinte da previdência social, 34 milhões em 2000, representava um pouco mais da sua metade, $52 \%$ (Gráfico 12). A quase totalidade dos contribuintes está na PIA, com uma grande concentração no grupo de 30 a 49 anos. Em termos absolutos, o formato das duas curvas é semelhante, ficando, logicamente, a de contribuintes mais abaixo. A modalidade permanece no grupo de 30 a 49 anos.

Levando em conta a população contribuinte da previdência social, 34 milhões em 2000, poder-se-ia calcular uma outra razão de dependência, baseada na relação entre contribuintes e não-contribuintes de todos os grupos etários: para cada 100 contribuintes, haveria 506 não-contribuintes. Uma relação completamente adversa para o sistema de seguridade social. Sem aumentar o número de pessoas ocupadas e, conseqüentemente, o número de contribuintes, facilitando seu acesso ao mercado de trabalho formal, maiores serão os encargos fiscais necessários para financiar as políticas relativas à seguridade social. Em outras palavras, o dividendo demográfico transitório só se efetivará, plenamente, se a razão de dependência demográfica estiver próxima da relação entre não-contribuintes de todas as idades e contribuintes. Uma observação deve ser feita: o primeiro dividendo refere-se a uma relação entre produtores e consumidores, segundo seus respectivos

GRÁFICO 11

População total ocupada e não-ocupada, segundo grupos etários Brasil - 2000

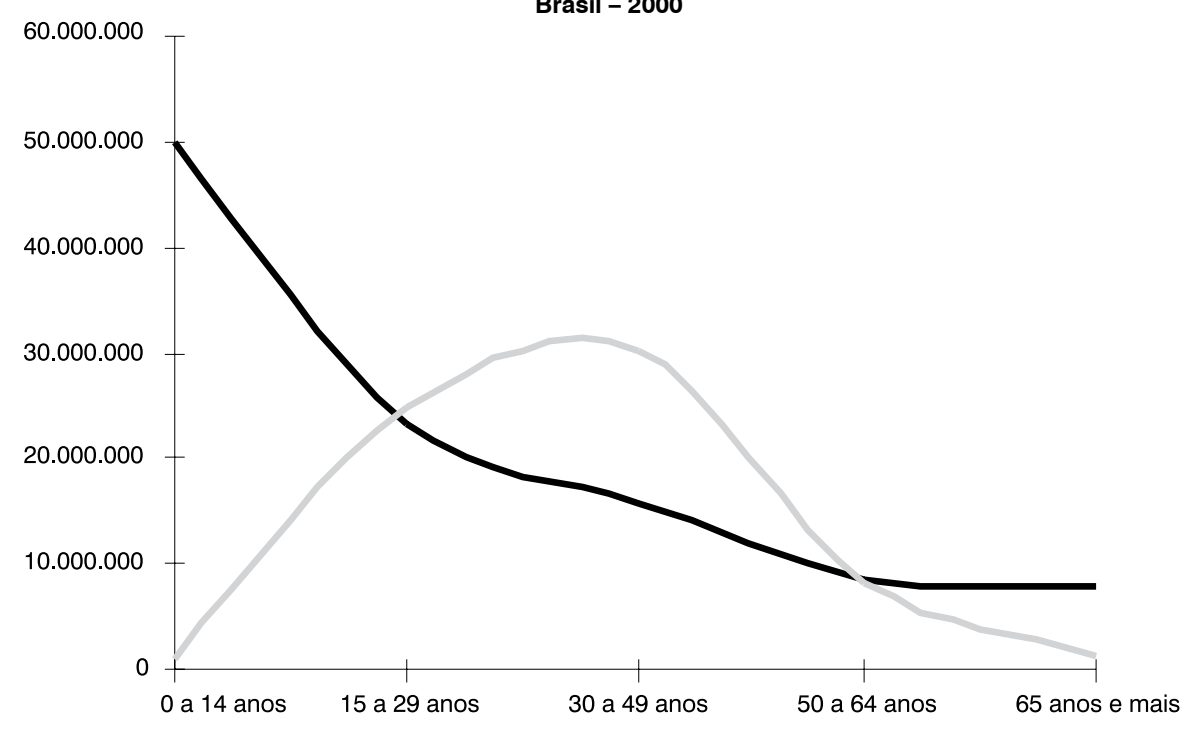

Não-ocupados $=$ Ocupados

Fonte: IBGE. Censo Demográfico de 2000. 


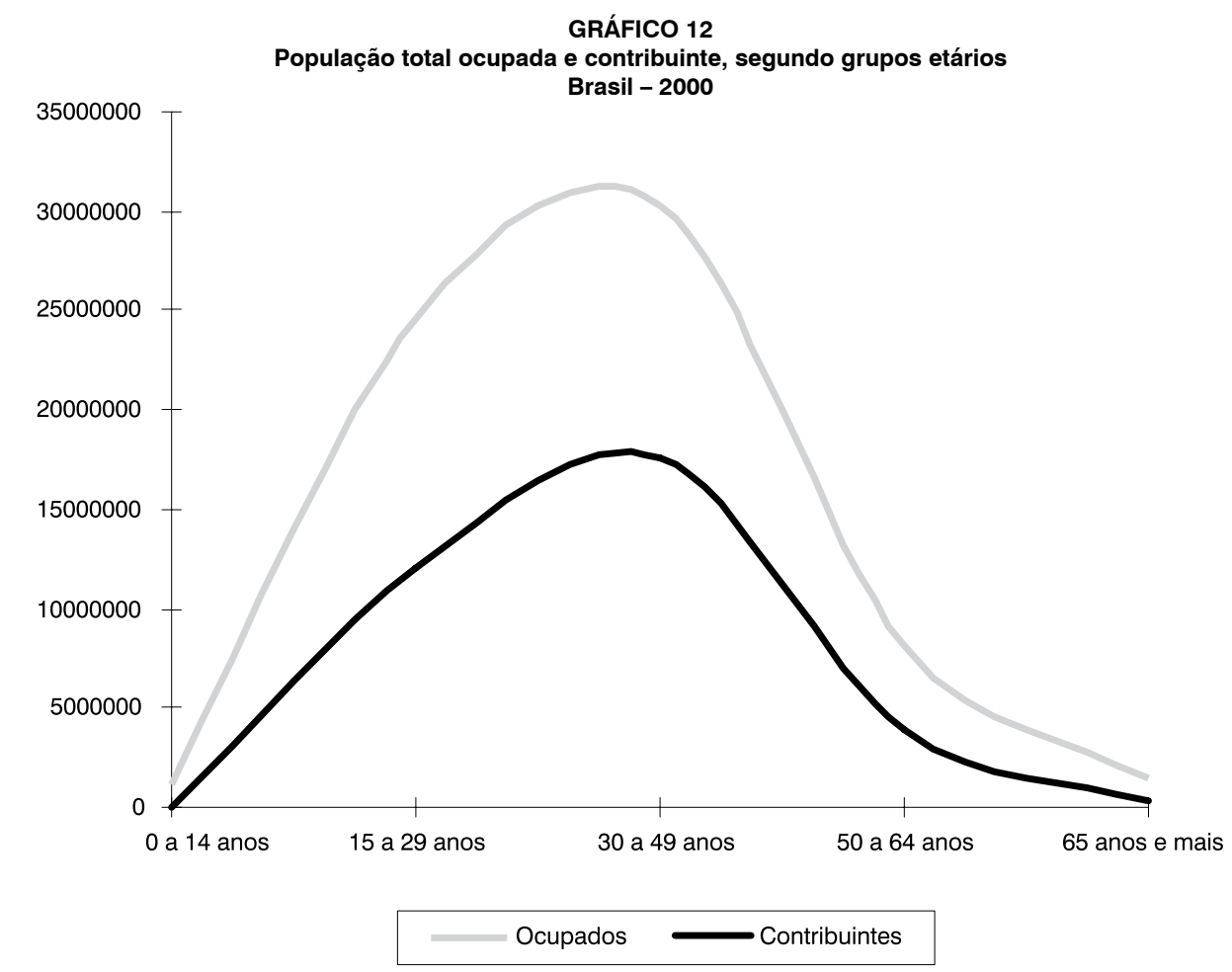

Fonte: IBGE. Censo Demográfico de 2000.

perfis etários, não podendo, portanto, ser retratado, exclusivamente, pelos indicadores do mercado de trabalho aqui analisados, apesar de estar intensamente condicionado por eles. Trata-se somente de um exercício para suscitar a imaginação analítica, sem a pretensão de testar a validade ou não da teoria dos bônus demográficos (BLOOM; CANNING; SEVILLA, 2003).

\section{Desequilíbrios regionais e sociais: possíveis conclusões sobre a transição demográfica e as desigualdades sociais}

No caso brasileiro, os desequilíbrios regionais tornam a discussão sobre as relações intergeracionais mais complexas. A razão de dependência total, assim como o índice dos idosos no Brasil, varia entre os Estados e regiões, segundo suas diferentes etapas na transição demográfica. A diferença entre a maior razão de dependência total, o Nordeste Setentrional, e a menor,
São Paulo, chega a 22 pessoas para cada 100 indivíduos em idade ativa (Tabela 5).

As proporções de jovens em relação à PIA da Região Norte e do Nordeste Setentrional ultrapassavam $60 \%$, enquanto a do Rio de Janeiro, a mais baixa razão de dependência dos jovens, ficava próxima de $37 \%$, em 2000. Próximos a esse último valor situavam-se São Paulo e o Extremo Sul. A diferença entre as razões de dependência dos jovens nos dois casos extremos, o Norte e o Rio de Janeiro, era de 26 jovens para cada 100 pessoas na PIA.

Somente as Regiões Norte e a CentroOeste tinham uma razão de dependência dos idosos menor do que a média nacional, ambas próximas a $6 \%$, contra $8 \%$ do total do Brasil. Novamente, o Rio de Janeiro é o destaque, com 11 idosos para cada 100 pessoas em idade ativa. No caso dos idosos, cuja proporção em relação à PIA cresce em velocidade menor do que diminui a dos jovens, a diferença entre os casos extremos, o 
TABELA 5

Razão de dependência total, de jovens e de idosos e índice de idosos, segundo regiões e alguns Estados do Brasil - 2000

\begin{tabular}{lcccc}
\hline \multirow{2}{*}{ Regióes } & \multicolumn{3}{c}{ Razão de Dependência } & \multirow{2}{*}{ Índice de Idosos } \\
\cline { 2 - 4 } & Total & Jovens & Idosos & 9,76 \\
Norte & 69,25 & 63,10 & 6,16 & 14,26 \\
NE Setentrional & 70,08 & 61,34 & 8,74 & 19,06 \\
NE Central & 62,91 & 52,84 & 10,07 & 17,61 \\
NE Meridional & 60,94 & 51,82 & 9,12 & 21,82 \\
Minas Gerais & 52,85 & 43,39 & 9,47 & 19,26 \\
Espírito Santo & 52,04 & 43,63 & 8,41 & 29,60 \\
Rio de Janeiro & 48,36 & 37,32 & 11,05 & 23,22 \\
São Paulo & 47,98 & 38,94 & 9,04 & 19,59 \\
Paraná & 52,33 & 43,76 & 8,57 & 24,50 \\
Extremo Sul & 50,05 & 40,20 & 9,85 & 14,21 \\
Centro Oeste & 51,93 & 45,47 & 6,46 & $\mathbf{1 8 , 2 8}$ \\
Brasil & $\mathbf{5 4 , 3 7}$ & $\mathbf{4 5 , 9 7}$ & $\mathbf{8 , 4 1}$ & \\
\hline
\end{tabular}

Fonte: IBGE. Censo Demográfico de 2000.

TABELA 6

Razão de dependência total, segundo renda domiciliar per capita Brasil - 1980-2000

Por 100 pessoas em idade ativa

\begin{tabular}{lccc}
\hline Renda domiciliar per capita (em salários mínimos) & $\mathbf{1 9 8 0}$ & $\mathbf{1 9 9 1}$ & $\mathbf{2 0 0 0}$ \\
\hline Menos de 0,5 SM & 108,41 & 89,86 & 81,90 \\
0,5 a 1 SM & 62,42 & 56,23 & 57,56 \\
1 a 2 SM & 43,57 & 45,10 & 46,36 \\
2 a 3 SM & 38,03 & 40,72 & 35,99 \\
3 a 5 SM & 38,95 & 39,34 & 34,37 \\
5 a 10 SM & 37,47 & 36,82 & 32,72 \\
Mais de 10 SM & 32,54 & 33,78 & 30,30 \\
Total & $\mathbf{7 4 , 5 9}$ & $\mathbf{6 6 , 3 3}$ & $\mathbf{5 5 , 1 9}$ \\
\hline
\end{tabular}

Fonte: IBGE. Censo Demográfico de 1980, 1991 e 2000.

Estado do Rio de Janeiro e a Região Norte, é menor: cinco idosos a mais, no Rio, para cada 100 pessoas na PIA.

Deve-se destacar que a distribuição etária proporcional da população de cada região ou Estado depende, além do comportamento da fecundidade das diversas unidades espaciais nas últimas décadas, de suas histórias migratórias. O declínio por mais tempo e mais rápido da fecundidade leva a uma menor proporção de jovens e maior de idosos, isto é, populações mais envelhecidas. Por outro lado, uma forte e persistente imigração tem como conseqüência o aumento da proporção da população jovem e daquela em idade ativa, com a conseqüente diminuição do segmento de idosos. Já nas unidades com forte emigração, seu efeito deveria ser um maior envelhecimento populacional (WONG; CARVALHO, 2006).

No caso do Brasil, mais importante do que as diferenças regionais são as so- ciais. As medidas estritamente ligadas às relações intergeracionais, como as razões de dependência e o índice de idosos, estão altamente correlacionadas aos níveis de renda per capita domiciliar. A tendência da razão de dependência total, no Brasil, independente dos grupos de renda, tem sido de redução. Todavia, nos dois subgrupos populacionais mais pobres, isto é, com renda domiciliar per capita inferior a um salário mínimo, era bem superior, em todos os períodos, à média nacional. No grupo mais pobre, em 2000, por exemplo, para cada 100 pessoas em idade ativa, havia 82 dependentes. Entre os mais ricos, aqueles com dez ou mais salários mínimos de renda domiciliar per capita, havia em torno de 30 pessoas dependentes, uma diferença muito expressiva, para menos, de cerca de 52 dependentes, em relação ao grupo mais pobre (Tabela 6).

A razão de dependência dos jovens apresenta declínio acentuado, generalizado 
e rapidamente decrescente à medida que a renda familiar per capita aumenta (Gráfico 13), o que seria de se esperar, sendo ela a causa da queda da razão total. Entre aqueles com renda familiar per capita acima de dez salários mínimos, a RDJ era de 17 por 100 ,

GRÁFICO 13

Razão de dependência de jovens, segundo renda domiciliar per capita (em salários mínimos)

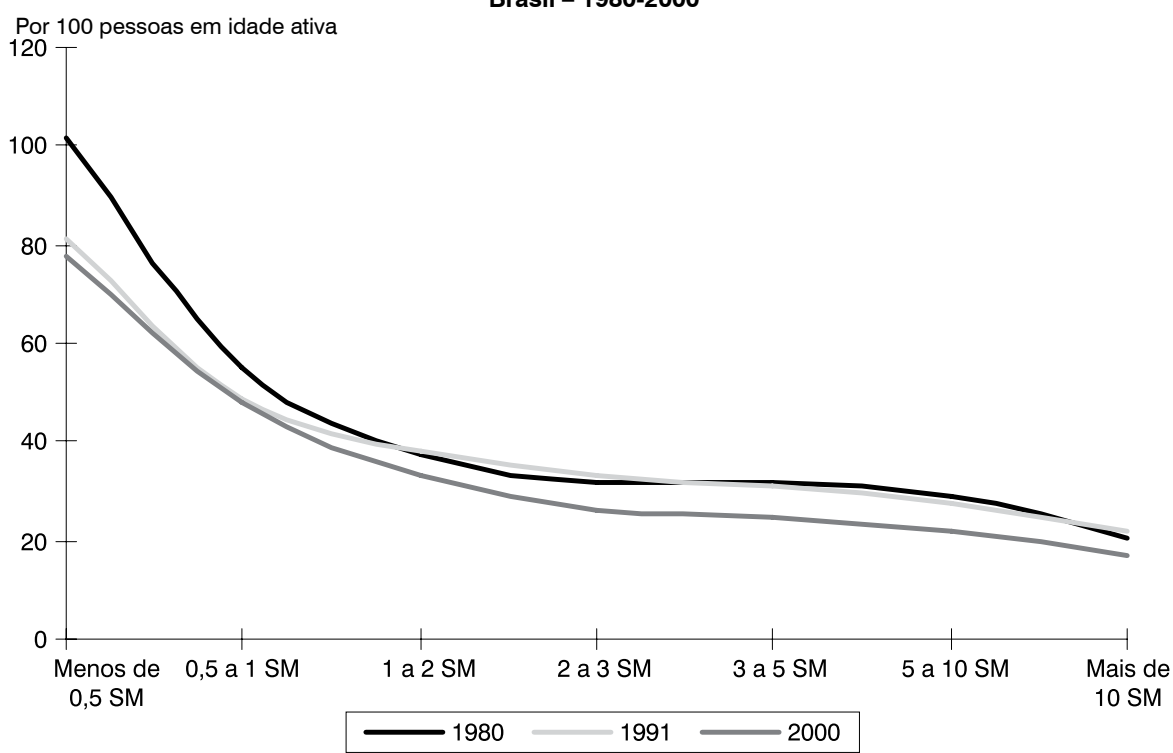

Fonte: IBGE. Censo Demográfico de 1980, 1991 e 2000.

GRÁFICO 14

Razão de dependência de idosos, segundo renda domiciliar per capita (em salários mínimos) Brasil - 1980-2000

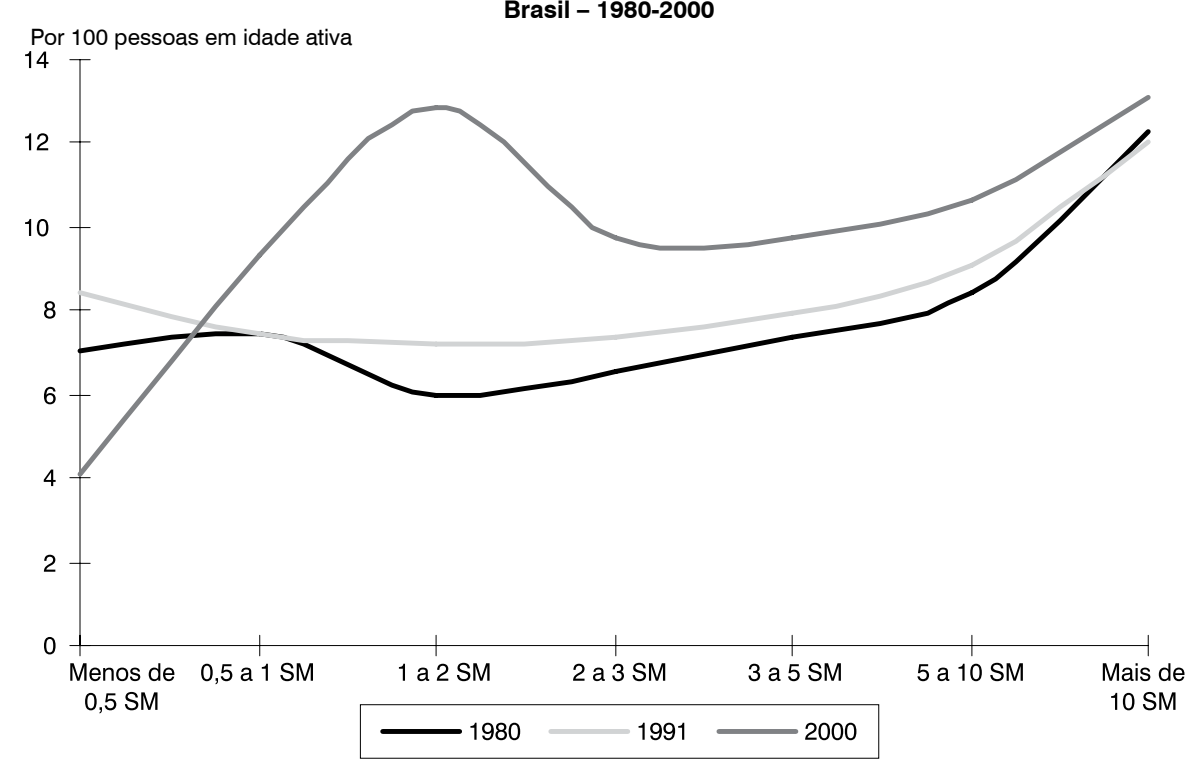

Fonte: IBGE. Censo Demográfico de 1980, 1991 e 2000. 
ou seja, 59 dependentes jovens a menos, para cada conjunto de 100 indivíduos em idade ativa, do que na população mais pobre, aquela com até um salário mínimo de renda domiciliar per capita.

Ao contrário da razão dos jovens, a dos idosos é crescente com a renda e o seu aumento tem sido mais lento, no período analisado (Gráfico 14). Entre os mais ricos, chegava, em 2000, a 14 idosos para cada 100 pessoas em idade ativa, 2,4 vezes maior do que entre os mais pobres. É importante observar a grande variação entre 1991 e 2000 na razão de dependência no grupo de um a dois salários mínimos, o que se deve, como foi mencionado anteriormente, a um grande aumento na proporção de idosos neste grupo, provavelmente em função dos efeitos das políticas constitucionais de transferência de renda.

$\mathrm{O}$ índice de idosos - outro indicador ligado às relações intergeracionais - também se mostra crescente com a renda em todos os períodos. Novamente, as diferenças entre 1991 e 2000 são significativas, principalmente para aqueles com um e dois salários mínimos de renda domiciliar, em que o índice dobra entre os dois últimos censos. Aqueles com renda de cinco a dez salários mínimos, em 2000, tinham um índice de idosos bastante alto, com quase um idoso para cada dois jovens. No grupo dos mais ricos, essa relação aumenta mais de valor, com aproximadamente 80 idosos para cada 100 jovens.

Os dados sobre as relações entre diversos indicadores da transição demográfica e a renda familiar per capita mostram que as diferenças sociais acarretam, no Brasil, "desigualdades demográficas" maiores do que aquelas observadas entre as diferentes regiões. A transição demográfica aparece, nitidamente, nas suas diferentes etapas, quando é analisada segundo as condições sociais e econômicas da população. Os benefícios ou os bônus demográficos, assim como os desafios políticos, são distintos, segundo os diferentes níveis sociais. Somente levando este fato fundamental em consideração é que as políticas públicas,

GRÁFICO 15

Índice de idosos, segundo renda domiciliar per capita (em salários mínimos) Brasil - 1980-2000

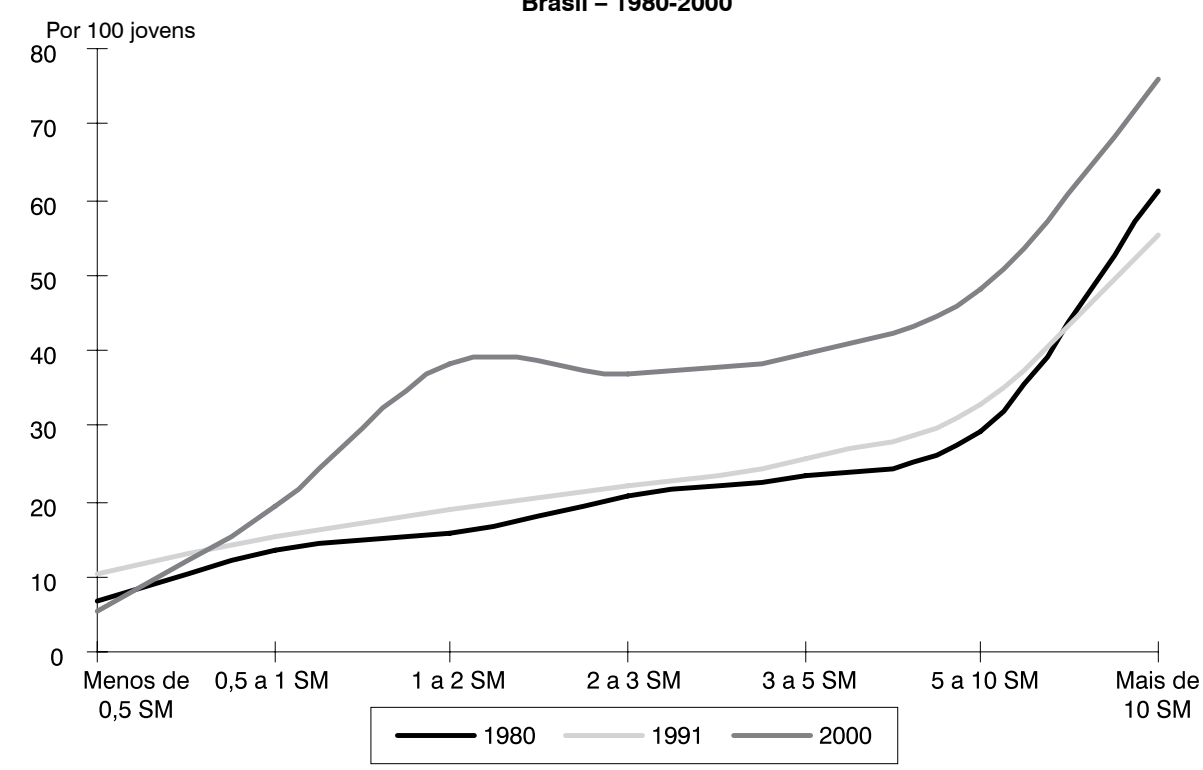

Fonte: IBGE. Censo Demográfico de 1980, 1991 e 2000. 
com o objetivo de justiça social, poderão bem aproveitá-los.

Mesmo que as relações intergeracionais tornem-se, com o tempo, menos heterogêneas, mas sem que se alterem as diferenças sociais de hoje, o crescimento demográfico diferenciado, segundo os grupos sociais, tornaria, no mínimo, estáveis as agudas desigualdades já hoje injustificáveis. Os pobres de hoje, mesmo numa hipótese otimista, reduzindo seu crescimento demográfico, até mesmo à sua mera reprodução, não deixarão de ser, somente por isso, menos pobres amanhã.

A capacidade de a transição demográfica potencializar as transferências intergeracionais de recursos está intimamente

\section{Referências bibliográficas}

BLOOM, D. E.; CANNING, D.; SEVILLA, $J$. Demographic transitions and the "demographic dividend". In: BLOOM, D. E.; CANNING, D.; SEVILLA, J. The demographic dividend: a new perspective on the economic consequences of population change. Santa Monica, Calif.: Rand, 2003.

BRITO, F. A transição demográfica no Brasil: as possibilidades e os desafios para a economia e a sociedade. Minas Gerais: Cedeplar, 2007 (Textos para a discussão, 318).

As idéias fora do tempo e do lugar: a polêmica recente sobre o malthusianismo. In: ENCONTRO NACIONAL DE ESTUDOS POPULACIONAIS, 15. Anais... Caxambu: Abep, 2006.

CONVÊNIO CEDEPLAR/MDS. Projeto de avaliação do beneficio de prestação continuada (BPC). Minas Gerais, 2006 (Relatório final).

GUZMÁN, J. M. Transición demográfica, bono demográfico, envejecimiento y transferencias intergeneracionales. In: CONGRESSO DE LA ASOCIACIÓN LATINOAMERICANA DE POBLACIÓN, 2, Guadalajara, 2006. La demografía latinoamericana del siglo XXI: desafíos, oportunidades e prioridades. associada à implementação de políticas que potencializem as transferências sociais desses mesmos recursos. Caso contrário, a transição demográfica vai gradativamente perdendo sua eficácia social, cada vez que se distancia dos grupos de renda mais altos.

Em síntese, não se trata de fechar os olhos aos possíveis benefícios gerados pelas mudanças demográficas, até porque, pela sua relevância estrutural, eles serão decisivos, positiva ou negativamente, do ponto de vista social. Desse modo, cabe à imaginação analítica e ao senso de justiça social colocá-los a serviço de políticas que tenham como objetivo fundamental reduzir as desigualdades sociais.

Guadalajara: Asociación Latinoamericana de Población, 2006.

IBGE - Instituto Brasileiro de Geografia e Estatística. Censos Demográficos de 1940, 1950, 1960, 1970 e 2000.

Indicadores sociodemográ-

ficos: prospectivos para o Brasil 1991-2030. Rio de Janeiro: Arbeit, 2006.

QUEIROZ, B. L.; TURRA, C. M.; PEREZ, E. R. The opportunities we cannot forget: economic consequences of population changes in Brazil. In: ENCONTRO NACIONAL DE ESTUDOS POPULACIONAIS, 15, Anais... Caxambu: Abep, 2006.

TURRA, C. M.; QUEIROZ, B. L. Before it's too late: demographic transition, labour supply and social security problems in Brazil. United Nations Expert Group Meeting on Social and Economic Implications of Changing Population Age Structures. México, Departamento de Assuntos Econômicos e Sociais. Divisão de População, 2005.

WONG, L.; CARVALHO, J. A. M. O rápido processo de envelhecimento do Brasil: sérios desafios para as políticas públicas. Revista Brasileira de Estudos de População, Abep, v.23, n.1, 2006 


\title{
Resumen
}

\section{Transición demográfica y desigualdades sociales en Brasil}

El artículo analiza la originalidad de la transición demográfica en Brasil determinada por los fuertes desequilibrios regionales y sociales. Aunque único, es un proceso global que alcanza a toda la sociedad brasileña, la transición demográfica se presenta como múltiple, pues se manifiesta en forma diferente, según las diversidades regionales y principalmente, sociales. Bajo esta perspectiva, la transición demográfica está lejos de ser considerada neutra: puede tanto crear posibilidades demográficas que potencien el crecimiento de la economía y del bienestar social de la población, como ampliar las graves desigualdades sociales que marcan a la sociedad brasileña. Esta situación se torna más compleja en función de que Brasil aún se encuentra inserto en el gran ciclo de crecimiento absoluto de su población. Debido a las desigualdades sociales y a las correspondientes diferencias en las tasas de fecundidad total, la población más pobre es la que más ha crecido, con fuertes consecuencias sobre los cambios en la estructura etaria. Las relaciones entre los diversos indicadores de la transición demográfica y los ingresos domiciliarios per cápita muestran que las diferencias sociales llevan en Brasil, a "desigualdades demográficas" mayores que aquéllas observadas entre las diferentes regiones. Sus beneficios, o bonos demográficos, son distintos según los niveles sociales. De este modo, la capacidad de que la transición demográfica potencie las transferencias intergeneracionales de recursos, está íntimamente asociada a la implementación de políticas que potencien las transferencias sociales de esos mismos recursos.

Palabras-clave: Transición demográfica. Bono demográfico. Desigualdad social.

\begin{abstract}
Demographic transitions and social inequalities in Brazil

This article examines the idiosyncrasies of demographic transitions in Brazil caused by the extreme disparities among regions and socioeconomic groups. While ubiquitous, demographic transition in Brazil shows a number of different facets. It is far from being a neutral process and creates opportunities as well as broad socioeconomic disparities. Because of differences in fertility rates by SES, those in lower-income brackets constitute the fastest growing populational group, as well as the group with the youngest age distribution. This article argues that socioeconomic differences are related to demographic disparities. Therefore, the development of public policies to improve the well-being of the poorest may help increase demographic dividends for the entire population.
\end{abstract}

Keywords: Demographic transition. Demographic dividends. Social inequalities.

Recebido para publicação em 14/12/2007. Aceito para publicação em 25/04/2008. 